УДК 316.344 .6

$10.17213 / 2075-2067-2021-2-121-129$

\title{
РЕПРОДУКТИВНЫЕ УСТАНОВКИ В РОССИЙСКОМ ОБЩЕСТВЕ: ПО ДАННЫМ ВСЕРОССИЙСКОГО СОЦИОЛОГИЧЕСКОГО ИССЛЕДОВАНИЯ ${ }^{1}$
}

\author{
(C) 2021 г. T. К. Ростовская, Е. А. Князькова
}

\section{Институт демографических исследований}

Федерального научно-исследовательского социологического центра РАН,

\section{2. Москва, Россия}

Цель исследования: изучение репродуктивных установок в различных социо-демографических группах с выделением молодежи как особого субъекта демографической политики.

Методологическую основу исследования составили концептуальные подходы социологии семьи в области формирования демографического развития, брачно-семейных, репродуктивных установок в различных социо-демографических группах.

Результаты исследования. $B$ статье представлены результаты Всероссийского соииологического исследования "Демографическое самочувствие России», позволившие охарактеризовать репродуктивное поведение россиян. Приведена детальная оценка репродуктивных установок по предпочитаемым числам детей и охарактеризованы препятствия к рождению желаемого числа детей. Предложены меры, способствуюшие росту деторождений.

Ключевые слова: репродуктивные установки; репродуктивное поведение; детность; демографическая политика.

\section{REPRODUCTIVE ATTITUDES IN RUSSIAN SOCIETY: ACCORDING TO THE ALL-RUSSIAN SOCIOLOGICAL RESEARCH}

\author{
(C) 2021 T. K. Rostovskaya, E. A. Knyazkova \\ Institute of Demographic Research of the Federal Research Sociological Center \\ of the Russian Academy of Sciences, Moscow, Russia
}

The purpose of the study: the study of reproductive attitudes in various socio-demographic groups, with the identification of young people as a special subject of demographic policy.

The methodological basis of the research is based on the conceptual approaches of family sociology in the field of demographic development, marital and family, and reproductive attitudes in various socio-demographic groups.

The results of the study. The article presents the results of the All-Russian sociological study "Demographic well-being of Russia», which allowed us to characterize the reproductive behavior of Russians. A detailed assessment of reproductive attitudes based on the preferred number of

1 Исследование выполнено за счет проекта Российского научного фонда №20-18-00256 «Демографическое поведение населения в контексте национальной безопасности России». 
children is given and the obstacles to the birth of the desired number of children are characterized. Measures that promote the growth of childbearing are proposed.

Key words: reproductive attitudes; reproductive behavior; childbirth; demographic policy.

Введение. Значимость вопросов грамотного управления демографическим развитием не теряет своей актуальности. Вторая волна депопуляции, начавшаяся в 2016 г. на фоне вступления в активный репродуктивный возраст относительно малочисленных поколений 1990-х гг. рождения и исчерпания ресурса рождаемости более старших поколений, peaлизовавших свои репродуктивные намерения при поддержке новых мер демографической политики, ставит задачу понимания возможностей демографического развития, в первую очередь, повышения рождаемости. Очевидно, в сложившихся условиях ключевой условно управляемой детерминантой рождаемости населения в России является репродуктивное поведение, которое тесно связано с брачным.

Для современной России характерна трансформация моделей демографического, в том числе репродуктивного поведения. Эта трансформация затрагивает и распределение ролей в семье. Предложенная в настоящее время концепция «гендерного перехода» теоретическая концепция, описывающая качественные изменения в демографическом развитии под влиянием фактора гендерного равенства - определяет на своем завершающем этапе достижение реального гендерного равенства (а не формального) во всех сферах общественной жизни, прежде всего при создании гендерно равных возможностей в трудовой сфере (чему, необходимо отметить, существенно способствует дистанционная занятость) и устранении дифференциации в заработной плате между мужчинами и женщинами.

В контексте изучения теоретико-методологической базы авторы проанализировали исследования ведущих ученых в области формирования демографического развития, брачно-семейных, репродуктивных устано- вок А.И. Антонова [1], В.А. Борисова [2], В.Н. Архангельского [3], Т.А. Гурко [4], Л.Л. Рыбаковского [6], С.В. Рязанцева [7], С. С. Сулакшина [8] и др.

Регулирование репродуктивного поведения молодежи будет эффективным при условии учета выявленных проблем демографической политики. Российские ученые обращают внимание на то, что государство может оказывать влияние на рождаемость населения посредством создания условий, способствующих реализации рождений [6].

Социо-демографический мониторинг «Демографическое самочувствие населения регионов России», проведенный авторами в 20192020 году, позволил получить данные о репродуктивных установках российской молодежи.

Материалы и методы. Статья подготовлена на данных Всероссийского исследования «Демографическое самочувствие России», проведенного путем анкетного опроса в конце 2019 - начале 2020 гг. исследовательским коллективом под руководством доктора социологических наук, профессора Т.К. Ростовской ${ }^{2}$.

Методологической основой исследования является теория репродуктивного поведения (А.И. Антонов, В.А. Борисов), рассматривающая его как систему действий и отношений, опосредующих рождение или отказ от рождения ребенка в браке или вне брака $[1,2]$. Ключевым звеном в структуре репродуктивного поведения является потребность в детях. А.И. Антонов определяет ее как «социально-психологическое свойство социализированного индивида, проявляющееся в том, что без наличия детей и подобающего их числа индивид испытывает затруднения как личность» $[1$, с. 110]. Т.К. Ростовская

2 Всероссийское социологическое исследование «Демографическое самочувствие России», проведенное в конце 2019 - начале 2020 гг. в десяти субъектах России: г. Москва, Республике Башкортостан, Республике Татарстан, Ставропольском крае, Вологодской, Волгоградской, Ивановской, Московской, Нижегородской и Свердловской областях. $\mathrm{N}=5616$ представителей различных поколений в возрасте от 18 до 50 лет. Рук. - д. соц. н., профессор Т.К. Ростовская. 
выделяет детность как основной критерий оценки благополучия молодой семьи [5]. В соответствии с утвержденной в 2007 году Концепцией государственной политики в отношении молодой семьи под благополучной молодой семьей понимается «семья, которая осуществляет свою жизнедеятельность в зарегистрированном браке, ориентирована на детей, имеет их, занимается их воспитанием и развитием на основе взаимодействия пространств семейного, общественного и государственного образования» [9].

Потребность в детях детерминируется социальными нормами детности и ценностными ориентациями, которые неразрывно связаны между собой и формируют систему потребностей.

Репродуктивное поведение. Репродуктивное поведение во многом зависит от представлений людей, о том, сколько, какого пола, когда и при каких условиях желательно рожать детей. Репродуктивные установки или ориентации в первую очередь выявляют по предпочитаемым числам детей.

Как и в ряде других исследований, была выявлена ориентация на двух-трехдетную семью при наличии всех необходимых условий: $41 \%$ хотели бы двоих детей, $26 \%$ троих (троих и более детей - 33\%, табл. 1). Среднее желаемое число детей составило 2,3. В Московской и Свердловской областях оно максимально - 2,5, выше среднего $(2,4)-$ в Республике Башкортостан.

Больше всего ориентированных на малодетность среди жителей Москвы (13\% хотели бы 1 ребенка даже при благоприятных условиях), Волгоградской области (13\%), Нижегородской области (10\%).

В гендерном разрезе некоторые различия в желаемом числе детей наблюдаются при ориентации на многодетность - среди мужчин доля хотевших бы троих и более детей выше, чем среди женщин (таблица 2). Молодежь до 30 лет ориентирована на малодетность заметно четче, чем население $30+$.

Расчет среднего желаемого числа детей по половозрастным группам подтверждает выявленные тенденции: мужчины старшей группы хотели бы в среднем больше детей, чем молодые и женщины-сверстницы; молодые, как женщины, так и мужчины, хотят детей меньше, чем в респонденты более старших возрастов. Как женщины, так и мужчи-

\section{Желаемое число детей}

Таблица 1

\begin{tabular}{|c|c|c|c|c|c|c|c|c|c|c|c|}
\hline \multicolumn{12}{|c|}{$\begin{array}{c}\text { Формулировка вопроса: Сколько детей (включая имеющихся) } \\
\text { Вы хотели бы иметь, если бы у Вас были все необходимые условия? }\end{array}$} \\
\hline Вариант ответа & 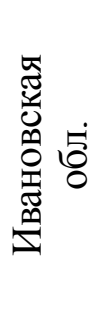 & 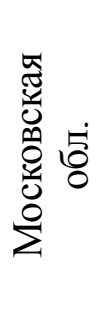 & 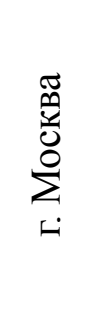 & 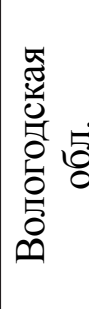 & 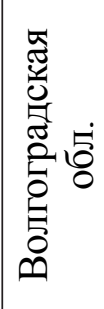 & 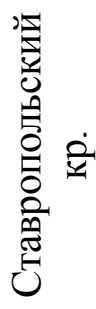 & 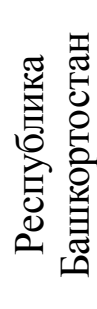 & 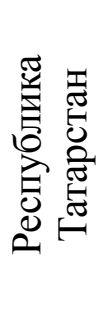 & 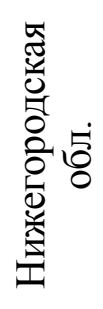 & 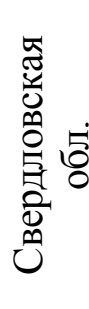 & 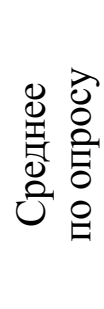 \\
\hline 0 & 0 & 2,1 & 5,5 & 3,6 & 5 & 2,9 & 7,7 & 3 & 5,9 & 3,4 & 4,1 \\
\hline 1 & 6,5 & 9,2 & 13,1 & 10 & 12,6 & 9,4 & 7,8 & 7,5 & 10,2 & 6,1 & 9,4 \\
\hline 2 & 48,7 & 41 & 39,5 & 44,7 & 39,7 & 45,9 & 30,4 & 37,2 & 49,2 & 41,4 & 41,3 \\
\hline 3 & 28,6 & 26,4 & 23,5 & 22,8 & 23,8 & 23,8 & 25,4 & 34,6 & 20,3 & 30,4 & 25,8 \\
\hline 4 & 0,6 & 2,6 & 2,9 & 3 & 3 & 3,1 & 3,1 & 4,7 & 2,5 & 3 & 2,9 \\
\hline 5 и более & 0 & 7,5 & 4,6 & 1,8 & 1,5 & 2,9 & 6,1 & 3,4 & 1,7 & 5,9 & 3,8 \\
\hline Трудно сказать & 15,6 & 11,1 & 10,9 & 14,2 & 14,5 & 12 & 19,5 & 9,7 & 10,2 & 9,9 & 12,7 \\
\hline $\begin{array}{l}\text { Среднее желаемое } \\
\text { число детей }\end{array}$ & 2,3 & 2,5 & 2,2 & 2,2 & 2,1 & 2,3 & 2,4 & 2,5 & 2,1 & 2,5 & 2,3 \\
\hline
\end{tabular}


ны всех возрастных категорий в большей степени ориентированы на рождение двоих детей даже при наличии необходимых условий (рис. 1).

С учетом имеющихся условий и оценки ситуации в целом в реальной жизни ориентируются на малодетность еще большее число россиян: планируют иметь двоих детей также около $40 \%$, а вот на многодетность ориентированы уже только 17\% (табл. 3). Среднее ожидаемое число детей составляет 1,9. Выше среднего его значение в Московской области и Республиках Башкортостан и Татарстан - 2,1.

По ожидаемому числу детей мужчины и женщины в целом единодушны. Различия просматриваются при анализе половозрастных групп (рис. 2). Сравнительно больше ориентированных на бездетность и однодетность среди молодежи, но среди них же и выше доля планирующих троих детей.

В целом структура населения по детности и репродуктивные ориентации свидетельствуют о закреплении малодетного типа репродуктивного поведения с ориентацией на 1-2 детей в семье. Хотели бы троих и более детей $33 \%$, тогда как реально планируют только $17 \%$ россиян.

Причины «недореализации» желаемых рождений, по мнению опрошенных россиян, кроются в материальных трудностях, неуверенности в будущем, жилищных проблемах.

Распределение ответов на вопрос «Сколько всего детей (включая имеющихся) Вы хотели бы иметь, если бы у Вас были все необходимые условия?», в \%

\begin{tabular}{|l|c|c|c|c|c|c|c|c|}
\hline \multirow{2}{*}{$\begin{array}{c}\text { Количество } \\
\text { детей }\end{array}$} & \multicolumn{3}{|c|}{$\begin{array}{c}\text { Женшины, распределение } \\
\text { по возрастам }\end{array}$} & $\begin{array}{c}\text { Мужчины, распределение } \\
\text { по возрастам }\end{array}$ \\
\cline { 2 - 9 } & $17-30$ & $30-40$ & $40-50$ & Всего & $17-30$ & $30-40$ & $40-50$ & Всего \\
\hline 0 & 4,4 & 2,2 & 2,7 & 3,1 & 6,7 & 4 & 2,6 & 4,4 \\
\hline 1 & 9,3 & 7,4 & 9,2 & 8,6 & 10,9 & 9,1 & 9,6 & 9,8 \\
\hline 2 & 47,1 & 41,4 & 40,2 & 42,9 & 44,3 & 40,7 & 31,4 & 38,8 \\
\hline 3 & 24,8 & 32,2 & 30 & 29 & 21,4 & 24,9 & 24,5 & 23,6 \\
\hline 4 & 2,6 & 3,1 & 3,3 & 3 & 2,2 & 3,3 & 2,1 & 2,5 \\
\hline 5 и более & 2 & 3,6 & 3,9 & 3,1 & 2,6 & 3,6 & 10,1 & 5,4 \\
\hline
\end{tabular}

\section{Среднее желаемое число детей}

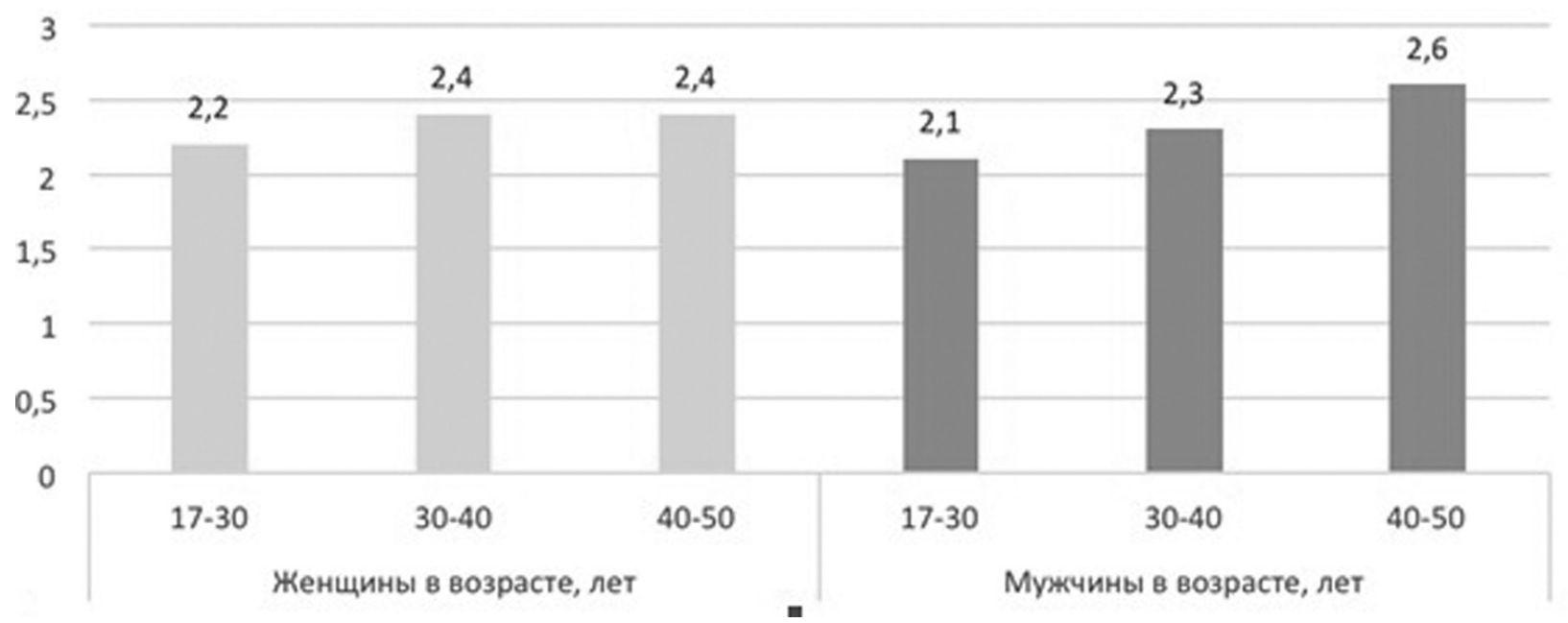

Рис. 1. Среднее желаемое число детей, половозрастной разрез, ед. 
Респонденты разных возрастов по-разному оценивают значимость отдельных причин, способных стать препятствиями для рождения желаемого числа детей. Так, для молодых респондентов (особенно мужчин) очень значима проблема отсутствия постоянной работы. Также респонденты отметили, что помехами в осуществлении рождения желаемого количества детей являются повышенная занятость на работе, сверхурочная работа, а также страх не реализовать собственные карьерные стратегии.

Наряду с этим для молодых людей важной причиной, объясняющей отсутствие детей, выступает отсутствие мужа или жены (таблица 4). Эти ответы еще раз обращают наше внимание на взаимосвязь репродуктивного и матримониального поведения откладывание вступления в брак или отказ от вступления в брак приводит к сокраще-

\section{Планируемое число детей}

Таблица 3

\begin{tabular}{|c|c|c|c|c|c|c|c|c|c|c|c|}
\hline \multicolumn{12}{|c|}{ Формулировка вопроса: Сколько детей (включая имеющихся) Вы собираетесь иметь? } \\
\hline Вари & 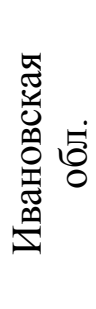 & 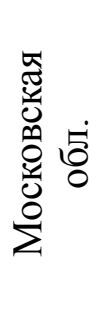 & 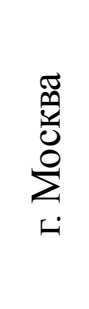 & 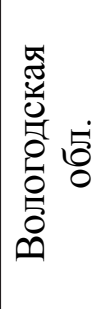 & 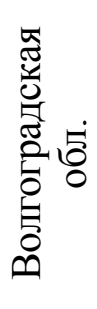 & 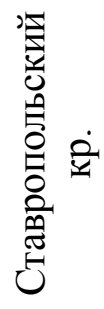 & 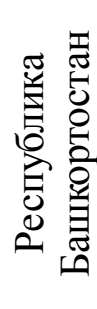 & 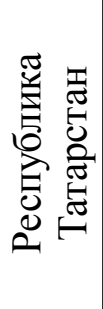 & 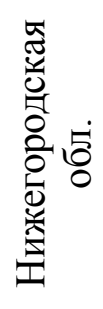 & 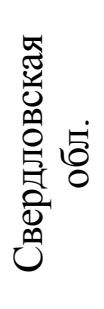 & 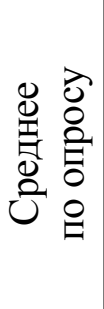 \\
\hline 0 & 6,5 & 4,8 & 8,7 & 2,7 & 4,9 & 4,3 & 6,9 & 4,2 & 5,7 & 4,2 & 5,2 \\
\hline 1 & 28,6 & 17,7 & 21,7 & 17,1 & 18 & 16,3 & 10,8 & 14,6 & 24,5 & 17,7 & 18,1 \\
\hline 2 & 42,2 & 40,3 & 35,7 & 47,5 & 40,5 & 46,6 & 31,3 & 44,5 & 45,3 & 46,5 & 41,9 \\
\hline 3 & 7,8 & 15,2 & 15,1 & 11,6 & 15,5 & 12,6 & 21,3 & 18,9 & 6,6 & 15,3 & 14,5 \\
\hline 4 & 0 & 2,2 & 1,1 & 1,2 & 1,9 & 2,6 & 3,1 & 2,9 & 0 & 1,2 & 1,7 \\
\hline 5 и более & 0 & 3,6 & 3,4 & 0,5 & 0,5 & 1,3 & 2,4 & 1,2 & 0,9 & 1,5 & 1,6 \\
\hline Трудно сказать & 14,9 & 16,1 & 14,4 & 19,4 & 18,7 & 16,3 & 24,2 & 13,7 & 17 & 13,7 & 17 \\
\hline $\begin{array}{l}\text { Среднее планируе- } \\
\text { мое число детей }\end{array}$ & 1,6 & 2,1 & 1,9 & 1,9 & 1,9 & 2 & 2,1 & 2,1 & 1,7 & 2 & 1,9 \\
\hline
\end{tabular}

\section{Среднее планируемое число детей}

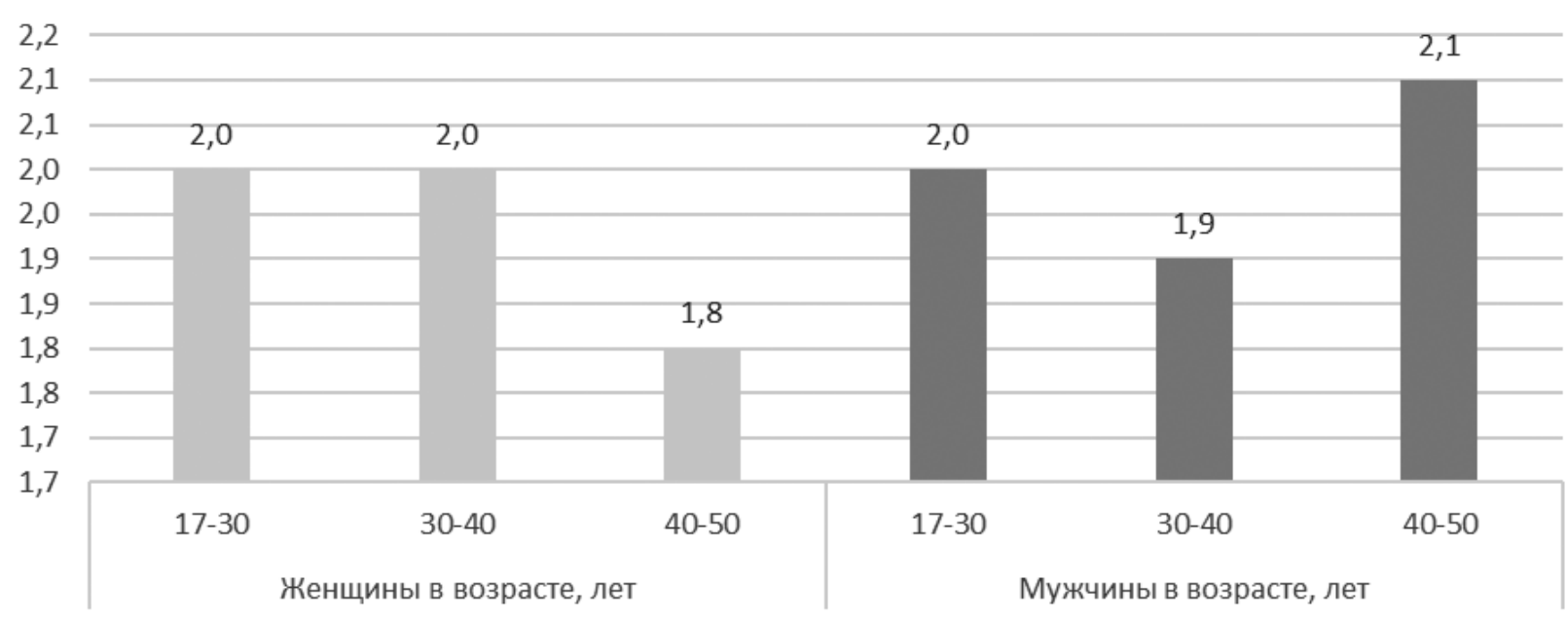

Рис. 2. Среднее ожидаемое (планируемое) число детей, ед. 
нию рождаемости или откладыванию рождения детей.

Важно, что молодые люди связывают отказ от рождения ребенка в настоящее время с состоянием своего здоровья в большей степени, чем лица более старшего возраста. Это свидетельствует либо о неудовлетворительном состоянии здоровья молодежи, либо о повышенном внимании к своему здоровью, его большей значимости на фоне значимости нескольких детей для семьи.

Молодежь в 40\% ответов «откладывает» рождение ребенка, люди 30-40 лет почти в $40 \%$ случаев уже достигли желаемой де- тности и больше не планируют детей. Среди последних больше и тех, кто ориентирован на деторождение в ближайшей перспективе.

В среднем, если оценивать распределение «откладываний» рождений по времени, больше половины планируется к реализации в трехлетний период. Очевидно, в большей степени молодежь откладывает рождение ребенка на 4 года и больше. Если использовать данные опроса для прогноза рождаемости, стоит обратить внимание на возможный провал в 4-летнем горизонте, на этот период запланировано меньше всего отложенных рождений $(12 \%)$.

Таблица 4

Распределение ответов респондентов на вопрос:

«Если Вы хотели бы иметь большее число детей, чем собираетесь, то что и в какой степени мешает лично Вам иметь желаемое число детей?» (вариант ответа «очень мешает», \% к числу ответивших)

\begin{tabular}{|c|c|c|c|}
\hline Варианты ответа & $\begin{array}{l}\text { Среднее } \\
\text { по опросу }\end{array}$ & Варианты ответа & $\begin{array}{l}\text { Среднее } \\
\text { по опросу }\end{array}$ \\
\hline Материальные трудности & 31,5 & $\begin{array}{l}\text { Работаю далеко от дома, много } \\
\text { времени трачу на дорогу }\end{array}$ & 9,9 \\
\hline Отсутствие работы & 21,4 & $\begin{array}{l}\text { Неудовлетворительное состоя- } \\
\text { ние моего здоровья }\end{array}$ & 9,9 \\
\hline $\begin{array}{l}\text { Неуверенность в завтрашнем } \\
\text { дне }\end{array}$ & 27,3 & $\begin{array}{l}\text { Не с кем будет оставить ребен- } \\
\text { ка, когда начну (жена начнет) } \\
\text { работать }\end{array}$ & 13 \\
\hline Жилищные трудности & 22,2 & $\begin{array}{l}\text { Неудовлетворительное состоя- } \\
\text { ние здоровья мужа (жены) }\end{array}$ & 8,5 \\
\hline Отсутствие мужа (жены) & 17,1 & Неудобный режим работы & 10,8 \\
\hline Большая занятость на работе & 14,9 & $\begin{array}{l}\text { Трудно устроить ребенка в хоро- } \\
\text { шие ясли или детский сад неда- } \\
\text { леко от дома }\end{array}$ & 10,5 \\
\hline $\begin{array}{l}\text { Трудности (для жены) совмеще- } \\
\text { ния работы вне дома и по дому, } \\
\text { сильно устаю (жена сильно уста- } \\
\text { ет) из-за «двойного рабочего дня» }\end{array}$ & 12 & $\begin{array}{l}\text { Стремление интереснее прово- } \\
\text { дить досуг }\end{array}$ & 8,2 \\
\hline $\begin{array}{l}\text { Стремление достичь успехов в } \\
\text { работе }\end{array}$ & 10,1 & $\begin{array}{l}\text { Сложности во взаимоотношени- } \\
\text { ях в семье }\end{array}$ & 9,3 \\
\hline Нежелание мужа (жены) & 11,1 & $\begin{array}{l}\text { Боязнь ущемить интересы име- } \\
\text { ющихся детей }\end{array}$ & 7,7 \\
\hline $\begin{array}{l}\text { Стремление должным образом } \\
\text { вырастить и воспитать уже име- } \\
\text { ющегося ребенка (детей) }\end{array}$ & 11,7 & $\begin{array}{l}\text { Родственники пока против рож- } \\
\text { дения еще ребенка (детей) }\end{array}$ & 5,1 \\
\hline
\end{tabular}


Среди мер поддержки семей при рождении детей вновь самыми значимыми стали те, которые направлены на способствование решению жилищных и материальных проблем, оказание медицинской помощи, а также поддержка семьи в период отпуска по уходу за ребенком, когда один из родителей теряет доход от трудовой деятельности. Значимы и такие аспекты, как досуг, более ранний выход на пенсию женщин с детьми, гибкий график работы. Очевидно, проблема совмещения трудовой деятельности и воспитания детей стоит достаточно остро, причем спектр ее проявлений широк - от потребности в детсадах для выхода матери на работу в связи с необходимостью заработка до сложностей параллельной реализации функций работника и родителя.

Заключение. Обобщая результаты проведенного исследования, необходимо отметить, что у россиян сформированы репродуктивные установки, позволяющие говорить о возможности хотя бы приближения к простому воспроизводству (среднее желаемое число детей составило 2,3), но при наличии всех необходимых условий.

Основными препятствиями на пути рождения желаемого числа детей, по мнению самих респондентов, выступают, прежде всего, материальные трудности и неуверенность в завтрашнем дне.

Исходя из мнений россиян о потребностях в мерах семейной и демографической политики, иелесообразно:

- в области повышения доступности жилья для семей с детьми продолжать развитие программ льготного ипотечного кредитования и субсидирования, в частности, уникальной региональной ипотечно-накопительной программы жилищных строительных сбережений. Для выполнения ею функции стимуляции рождения детей ее совершенствование должно быть направлено на большую ориентацию на молодые семьи, ожидающие детей, и семьи, имеющие малолетних детей. В рамках программы для этих категорий семей могут быть введены дополнительные поощрительные условия участия;

- уделять повышенное внимание профилактике разводов. Необходимо наладить работу социально-психологического сопровождения семей, испытывающих трудности в налаживании отношений, ведении быта, воспитания детей. Высокий уровень разводимости и слабая защищенность интересов ребенка после развода родителей (алименты недостаточная мера) не позволяет и женщинам планировать рождение более 1 ребенка, т.е. только одного ребенка женщина может достойно воспитать и материально обеспечить, но не больше. В этом отношении хороши меры, принимаемые государством в случаях, если жилье куплено в совместную собственность с использованием материнского капитала и иных семейных субсидий (жилье приобретается в совместную собственность детей и родителей). Однако при приобретении жилья в совместную собственность без привлечения государственных средств после развода собственность делится между родителями, интересы детей не учитываются;

- актуально формирование развитой системы ухода и присмотра за детьми младшего школьного возраста с целью создания возможности совмещения родителями обязанностей по воспитанию детей с профессиональной занятостью. Тем не менее, учредители образовательных организаций самостоятельно решают вопрос, связанный с оплатой т.н. «продленки» в школах. Так, Закон №273-Ф3 от 29.12.2012 г. «Об образовании в Российской Федерации» (статья 66, пункт 8) предусматривает возможность оплаты посещения группы продленного дня, но не устанавливает ее обязательности. Кроме того, учредитель имеет право снизить размер этой платы или вовсе не взимать ее с отдельных категорий родителей (законных представителей) несовершеннолетних обучающихся. Отметим: платность групп продленного дня может сделать затруднительным посещение их детьми из малообеспеченных семей;

- осуществлять поддержку вовлеченного отцовства. Существует корпоративноведомственный опыт выплаты регулярной премии (надбавки к заработной плате) сотрудникам-мужчинам, чьи жены находятся в отпуске по уходу за ребенком. Эффект меры обусловлен не столько реальным вкладом в бюджет семьи, сколько усилением социально-психологической репродуктивной мотивации мужчин. Введение отпуска по уходу за ребенком для отцов будет способствовать формированию более тесной связи между от- 
цом и детьми (если данный отпуск не будет отцом востребован, то и мать им воспользоваться не сможет). Такие меры могут благоприятно сказаться на формировании гендерного равенства на рынке труда (например, работодатели перестанут при приеме на работу отдавать предпочтение мужчинам, что позволит женщине быть увереннее в себе при планировании времени рождения ребенка);

- активно формировать репродуктивные установки в обществе. Нужно усилить информационно-просветительскую компоненту демографической политики. Поиск конкретных механизмов, форм и инструментов лежит в области маркетинга. Определенно можно констатировать эффективность использования в данной деятельности нового образа современной семьи, основанной на любви и свободе выбора, социальной и экономической целесообразности (успешности), семьи как фактора счастья и благополучия, безусловной поддержки и принятия.

Данный перечень мер не является исчерпаемым. Но в современных условиях без проведения активной демографической, семейной политики переломить сложившийся тренд ссуженного воспроизводства не представляется невозможным.

\section{Литература}

1. Антонов А.И. Динамика населения России в XXI веке и приоритеты демографической политики / А.И. Антонов, В.А. Борисов. - М.: Ключ-С, 2006. - 192 с.

2. Борисов В. А. Демография / В. А. Борисов. - M.: NOTABENE, 2001. - 272 c.

3. Архангельский В.Н. Помощь семьям с детьми в России: оценка демографической результативности // СОЦИС. - 2015. №3. - С. 6.

4. Гурко Т.А. Динамика брачных установок и планов студентов // Социологические исследования. - 2019. - №7. - С. 102-113.

5. Ростовская T.K. Благополучие молодой семьи - основа качества жизни молодежи. Международный академический вестник. - 2014. - №1. - С. 30-33.

6. Рыбаковский Л. Л. 20 лет депопуляции в России. - М.: Экон-информ, 2014. - 231 с.

7. Демографическое развитие России: тенденции, прогнозы, меры. Национальный демографический доклад - 2020 / С. В. Рязанцев, В.Н. Архангельский, О.Д. Воробьева и др.; отв. ред. С. В. Рязанцев. - М.: ООО «Объединенная редакция», 2020. - 156 с.

8. Государственная политика вывода России из демографического кризиса / под ред. С. С. Сулакшина. - М., 2007. - 888 с.

9. Письмо МинобрнаукиРФ от 08.05.2007 г. №AФ-163/06 «О Концепции государственной политики в отношении молодой семьи» [Электронный ресурс]. - Режим доступа: http:// docs.cntd.ru/document/902060617 (Дата обращения: 15.03.2021).

\section{References}

1. Antonov A.I. Dinamika naselenija Rossii v XXI veke i prioritety demograficheskoj politiki [Dynamics of the population of Russia in the XXI century and priorities of demographic policy] / A. I. Antonov, V.A. Borisov. - Moscow: Kljuch-S, 2006. - 192 p.

2. Borisov V.A. Demografija [Demografiya] / V.A. Borisov. - Moscow: NOTABENE, 2001. - $272 \mathrm{p}$.

3. Arhangel'skij V.N. Pomoshh' sem'jam s det'mi v Rossii: ocenka demograficheskoj rezul'tativnosti [Assistance to families with children in Russia: an assessment of demographic performance] // SOCIS. - 2015. - №3. - P. 6.

4. Gurko T.A. Dinamika brachnyh ustanovok i planov studentov [Dynamics of marriage attitudes and plans of students] // Sociologicheskie issledovanija [Sociological researches]. — 2019. - №7. - Pp. 102-113.

5. Rostovskaja T.K. Blagopoluchie molodoj sem'i - osnova kachestva zhizni molodezhi. Mezhdunarodnyj akademicheskij vestnik [The well-being of a young family is the basis of the quality of life of young people. International Academic Bulletin]. — 2014. — №1. - Pp. 30-33.

6. Rybakovskij L.L. 20 let depopuljacii v Rossii [20 years of depopulation in Russia]. Moscow: Jekon-inform, 2014. — $231 \mathrm{p}$.

7. Demograficheskoe razvitie Rossii: tendencii, prognozy, mery. Nacional'nyj demograficheskij doklad — 2020 [Demographic development of Russia: trends, forecasts, measures. National demographic report-2020]/S. V. Rjazancev, V.N. Arhangel'skij, O.D. Vorob'eva i dr.; in S. V. Rjazancev (eds.). - Moscow: OOO «Ob'edinennaja redakcija», 2020. - $156 \mathrm{p}$. 
8. Gosudarstvennaja politika vyvoda Rossii iz demograficheskogo krizisa [State policy of Russia's withdrawal from the demographic crisis] / in S. S. Sulakshin (eds.). - Moscow, 2007. - 888 p.

9. Pis'mo Minobrnauki RF ot 08.05.2007 g. №AF-163/06 «O Koncepcii gosudarstvennoj politiki $\mathrm{v}$ otnoshenii molodoj sem'i» [Letter of the Ministry of Education and Science of the Russian Federation dated 08.05.2007 №AF-163/06 «On the concept of state policy in relation to the young family»] [Jelektronnyj resurs]. — URL: http://docs.cntd.ru/document/902060617 (Date accessed: 15.03.2021).
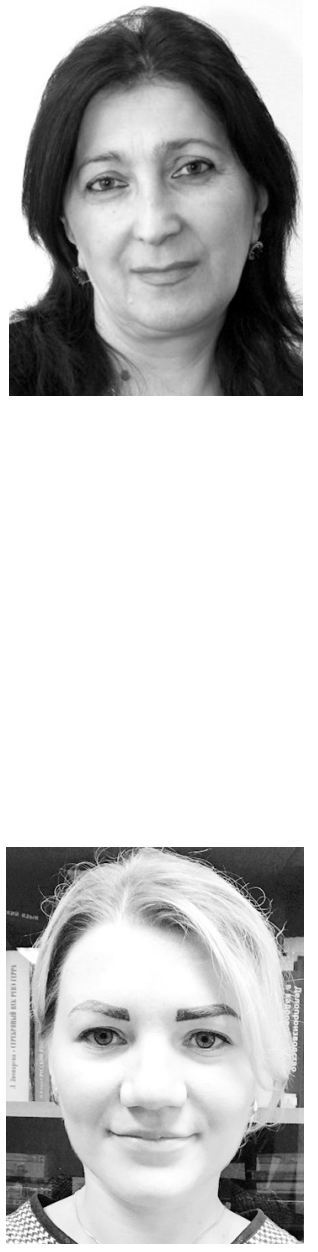

Ростовская Тамара Керимовна - доктор социологических наук, профессор, заместитель директора по научной работе Института демографических исследований Федерального научно-исследовательского социологического центра Российской академии наук.

Rostovskaya Tamara Kerimovna - Doctor of Sociological Sciences, Professor, Deputy Director for research, Institute of Demographic Research of the Federal Research Sociological Center, Russian Academy of Sciences.

119333, г. Москва, ул. Фотиевой, 6, стр. 1 6 Fotievoj st., bld. 1, 119333, Moscow, Russia

E-mail: rostovskaya.tamara@mail.ru

Князькова Екатерина Александровна - кандидат политических наук, старший научный сотрудник отдела семьи и семейно-демографической политики Института демографических исследований Федерального научно-исследовательского социологического центра Российской академии наук.

Knyazkova Ekaterina Alexandrovna - Candidate of Political Sciences, Senior Researcher of the Department of Family and Family-Demographic Policy, Institute of Demographic Research of the Federal Research Sociological Center of the Russian Academy of Sciences.

119333, г. Москва, ул. Фотиевой, 6, стр. 1 6 Fotievoj st., bld. 1, 119333, Moscow, Russia E-mail: Eapavlova@bk.ru 